\title{
Ambiente Contábil
}

\section{REVISTA AMBIENTE CONTÁBIL}

Universidade Federal do Rio Grande do Norte

ISSN 2176-9036

Vol. 11, n. 1, Jan./Jun, 2019

Sítios: http://www.periodicos.ufrn.br/ambiente

http://www.atena.org.br/revista/ojs-2.2.3-06/index.php/Ambiente

Artigo recebido em: 24.05.2018. Revisado por pares em: 19.09.2018. Reformulado em: 18.10.2018. Avaliado pelo sistema double blind review.

DOI: 10.21680/2176-9036.2019v11n1ID14337

Profissionais da controladoria: competências e demandas organizacionais

Controller professionals: competencies and organizational demands

Profesionales de la controladora: competencias y demandas organizacionales

\section{Tania Nobre Gonçalves Ferreira Amorim}

Doutora em Administração, Professora Associada da Universidade Federal Rural de Pernambuco, Docente do Mestrado em Controladoria, Departamento de Administração, Endereço: Rua do Espinheiro, 835 - Recife/PE, (81) 33205403. Identificadores (ID):

Lattes: http://lattes.cnpq.br/2951129655100886,

ORCID iD: https://orcid.org/0000-0002-9927-4241

E-mail: tanobre@gmail.com

\section{Ladjane de Barros Silva}

Mestre em Administração, Servidora da Universidade de Pernambuco - UPE / PROCAPE, Tutora Externa de Graduação EaD do Centro Universitário Leonardo da Vinci - UNIASSELVI - Polo Recife-PE, Endereço: Rua dos Palmares, s/n - Santo Amaro, Recife - PE, (81) 31817100. Identificadores (ID):

Lattes: http://lattes.cnpq.br/0004856095658604,

ORCID iD: https://orcid.org/0000-0002-0317-7018

E-mail: ladbarros@yahoo.com.br

\section{Resumo}

Objetivo: Identificar as principais competências exigidas aos Controllers para o exercício de suas atividades em empresas que estão instaladas em Pernambuco, Brasil.

Metodologia: A pesquisa foi descritiva e exploratória, realizada em empresas que tivessem pelo menos um profissional ocupando a função de controller, contador gerencial ou controlador. O questionário foi o instrumento de coleta de dados desenvolvido com base no levantamento bibliográfico, focando nas competências individuais e suas categorias: competências de negócios, técnico-profissionais e sociais.

Resultados: 100 profissionais aceitaram participar do estudo. 40\% das empresas eram de grande porte e a maioria era prestadora de serviços, com controladoria na estrutura organizacional. Os controllers eram maioria homens, com menos de 40 anos, 10 anos de experiência, ocupando função gerencial e com formação superior. As competências técnicas individuais que a maioria dos controllers afirmou "usar muito" foram seis, dentre as 20 listadas: assessora a cúpula administrativa, tem conhecimentos na área contábil, elabora relatórios 
gerenciais, fornece suporte informacional à gestão empresarial, realiza análise de custos e tem conhecimentos na área financeira. As competências de negócios, das 18 apresentadas, 4 são muito utilizadas: Pensa e age estrategicamente, orientação para resultados, busca melhoria contínua dos processos em que participa e foco na qualidade das decisões tomadas. E dentre as 18 competências sociais, a maioria respondeu "usar muito", 14, relacionadas ao trabalho íntegro, proativo, flexível e realizador, com ênfase na interação e liderança da equipe, com controle emocional e boa adaptação às mudanças. Atualmente, a controladoria vem ampliando sua esfera de atuação nas organizações, consolidando-se como unidade de apoio à gestão organizacional.

Contribuições: A pesquisa mostra que os controladores possuem pós-graduação, com responsabilidade pelos controles internos e gerenciais das organizações, atuando no nível gerencial e administrativo, além de desenvolver uma gama de competências.

Palavras-chave: Controladoria, Competências, Perfil Profissional, Controller, Gestão organizacional.

\begin{abstract}
Objective: Identify the main competencies required of Controllers to carry out their activities in companies that are located in Pernambuco, Brazil.

Methodology: The research has descriptive and exploratory characteristics, carried out in companies that have at least one professional, occupying the position of controller or managerial accountant. The questionnaire was the data collection tool developed based on the bibliographical survey, focusing on the individual competences and their categories: business, technical-professional and social skills.
\end{abstract}

Results: A total of 100 professionals accepted to participate in the study. Based on the number of employees, about $40 \%$ of the companies were large. Most companies were service providers with a controlling sector established in the organizational structure. As for the profile of controllers identified, most of them were male, with less than 40 years, 10 years of experience in the function, occupying a managerial role and with a higher education. The individual technical competencies that most controllers said "use a lot" were six of the 20 listed, presented in decreasing order of use: Advises the administrative leadership, has knowledge in the accounting area, elaborates management reports, provides informational support to business management, performs cost analysis and has expertise in the financial area. The 18 business skills presented, 4 are widely used: Thinks and acts strategically, results orientation, seeks continuous improvement of the processes in which it participates and focus on the quality of the decisions made. And among the 18 social skills, most responded "to use a lot" 14, related to the integrity, proactive, flexible and fulfilling work, with emphasis in the interaction and leadership of the team, with emotional control and good adaptation to the changes. Currently, the controllership has been expanding its sphere of action in organizations, consolidating itself as a support unit for organizational management.

Contributions: The research shows that the controllers has a postgraduate degree, with responsibility for the internal and managerial controls of the organizations, working at the managerial and administrative level, besides developing a range of competencies. 
Keywords: Controlling sector, Skills, Professional Profile, Controller, Organizational Management.

\section{Resumen}

Objetivo: Identificar las principales competencias exigidas a los Controllers para el ejercicio de sus actividades en empresas que están instaladas en Pernambuco, Brasil.

Metodología: La investigación fue descriptiva y exploratoria, realizada en empresas que tuvieran al menos un profesional, ocupando la función de controlador o contador gerencial. El cuestionario fue el instrumento de recolección de datos desarrollado con base en el levantamiento bibliográfico, enfocándose en las competencias individuales y sus categorías: competencias de negocios, técnico-profesionales y sociales.

Resultados: 100 profesionales aceptaron participar del estudio. El 40\% de las empresas eran de gran tamaño y la mayoría era prestadora de servicios, con sector de Contraloría en la estructura organizacional. Los controladores eran mayoría masculina, con menos de 40 años, 10 años de experiencia, ocupando función gerencial y con formación superior. Las competencias técnicas individuales que la mayoría de los controllers afirmó "usar mucho" fueron seis, entre las 20 listadas: Asesora la cúpula administrativa, tiene conocimientos en el área contable, elabora informes gerenciales, proporciona soporte informacional a la gestión empresarial, realiza análisis de costos y tiene conocimientos en el área financiera. Las competencias de negocios, de las 18 presentadas, 4 son muy utilizadas: Piense y actúa estratégicamente, orientación hacia resultados, busca mejora continua de los procesos en que participa y foco en la calidad de las decisiones tomadas. Y entre las 18 competencias sociales, la mayoría respondió "usar mucho", 14, relacionadas al trabajo íntegro, proactivo, flexible y realizador, con énfasis en la interacción y liderazgo del equipo, con control emocional y buena adaptación a los cambios. Actualmente, la Contraloría viene ampliando su esfera de actuación en las organizaciones, consolidándose como unidad de apoyo a la gestión organizacional.

Contribuciones: La investigación muestra que el profesional de controlador posee un posgrado, con responsabilidad sobre los controles internos y gerenciales de las organizaciones, a nivel gerencial y de apoyo a la cumbre administrativa, desarrollando una gama de competencias.

Palabras-Clave: Contraloría, Competencias, Perfil profesional, controlador, Gestión organizacional.

\section{Introdução}

As organizações estão sujeitas a uma maior competição, controles e demandas, na atualidade. Com isto, a gestão interna tem sido afetada e é neste ponto que muitas organizações incorporaram em suas estruturas uma unidade de controle interno e apoio à gestão, que normalmente é denominada de controladoria. A controladoria, contudo, também é vista como um campo de conhecimento humano que possui seus fundamentos e métodos muito embasados em outras ciências, mas voltados ao controle da gestão organizacional. Assim, a lacuna teórica que embasa a atuação da Controladoria nas organizações modernas, defende que a controladoria apoia e coordena os sistemas organizacionais que influenciam na gestão, pessoas, práticas e 
normas organizacionais (Borinelli, 2006; Morante \& Jorge, 2008; Crispim, Cabral, \& Libonati, 2011; Monteiro, \& Barbosa, 2011).

Assim, a controladoria tem acompanhado a evolução da gestão organizacional atuando no controle da dinâmica interna, influenciando crenças e valores organizacionais (Broadbent, \& Laughlin, 2005; Barreto, 2008; Beuren, \& Miiler, 2010).

Machado, Lunkes, Petri e Rosa (2010, p.26) defendem que "as organizações contemporâneas têm experimentado pressões competitivas sem precedentes, sendo assim forçadas a criar continuadamente mecanismos para diferenciar-se e incrementar seus níveis de competitividade". Então, a controladoria serve de apoio à gestão para atender a essas pressões, fornecendo respostas rápidas e atuais à cúpula organizacional.

O responsável pela controladoria ou controles gerenciais, pode receber diversas denominações como controller, contador gerencial ou controlador. Muitas organizações no Brasil adotam a denominação de controller, a qual será também utilizada neste artigo. Este profissional evoluiu em suas funções e competências, a fim de atender efetivamente às demandas organizacionais. Inicialmente realizava basicamente atividades de controles operacionais, mas tem assumido novas funções no apoio aos processos de tomada de decisões gerenciais, nos mais variados níveis. Em muitas organizações, é responsável por medir e informar o desempenho financeiro, então o ponto de partida das suas competências é a contabilidade, ampliado por conhecimentos em sistemas de informações gerenciais, gestão de pessoas, planejamento e avaliação de desempenho, dentre outros (Anthony, \& Govindarajan, 2004; Koliver, 2005; Zoni, \& Kenneth, 2007; Vargas, \& Beuren, 2012; Lunkes, Schnorrenberger, \& Rosa, 2013; Vogt, Degenhart, \& Lavarda, 2017).

Assim, o estudo sobre a controladoria e seus profissionais passou a atrair maior interesse, para os estudos da dinâmica da gestão organizacional, fomentando pesquisas nacionais e internacionais. Então, a controladoria é fundamentada por preceitos básicos da contabilidade, mas galgou novos horizontes na realidade organizacional atual (Buscoa, Quattroneb, \& Riccabonia, 2007; Lunkes et al., 2013).

Com a concorrência acirrada e as dificuldades econômicas impostas às organizações, $\mathrm{o}$ controle de suas atividades passa a ser importante aliado da gestão, que busca ser coerente com o momento de redução ou redirecionamento de estruturas, processos e mecanismos de prestação de serviços e produção, para galgar ou mesmo se manter competitivo, atendendo às demandas dos consumidores, legislação e comunidade em geral. Nascimento e Reginatto (2007, p. 65) destacam que "a qualidade das decisões tomadas pelos gestores depende da qualidade das informações disponibilizadas, as quais são imprescindíveis à realização das funções da área de controladoria e ao processo decisório". Assim, pode-se constatar que muitas organizações passaram a incorporar, mais efetivamente em suas estruturas organizacionais, uma unidade de controladoria, ou mesmo suas atividades, a partir do entendimento de sua importância para a gestão estratégica e competitividade organizacional.

Portanto, diante dessa problemática atual e instigante, a atuação dos profissionais que serão responsáveis por atender a todas essas demandas de controle interno e externo à gestão organizacional precisa estar em consonância com essas exigências diversificadas e não mais em termos apenas operacionais, mas em apoio à gestão tática e estratégica. Isto representa um avanço na carreira do controller que inicialmente desenvolvia apenas um trabalho rotineiro e de apoio operacional, mas com as novas exigências de competitividade organizacional suas atividades estão deixando de ser meramente operacionais para atuarem de forma efetiva como apoio à gestão organizacional e planejamento organizacional, como defendem Borinelli (2006), Lunkes et al. (2013) e Schmidt e Santos (2014), dentre outros. 
Assim, a formação em Ciências Contábeis não está mais atendendo às novas competências que são exigidas desse profissional, necessitando de uma ampla gama de competências comportamentais e gerenciais que não estão comtempladas na formação em nível de bacharelado. Competências nas áreas administrativa, econômica, legal, e até mesmo da área comportamental e de liderança, estão incluídas no rol de competências que são esperadas para o controller. Beuren e Almeida (2012) relatam que as atividades dos controllers são práticas sociais, que envolvem procedimentos e métodos diversos, com atividades complexas e variadas. Concluindo, Oro, Beuren e Carpes (2013, p. 17) salientam que "a formação profissional em qualquer área é principiada por uma sólida formação acadêmica e continuada pela aplicação prática da sua inserção no mercado de trabalho".

Já Gomes, Souza e Lunkes (2014), salientam que as principais funções da controladoria envolvem planejamento, controle, contabilidade, sistemas de informações e gestão de pessoas, o que vai além da formação em nível de bacharelado em Ciências Contábeis. Por sua vez, Souza, Barros, Araújo e Silva (2013) defendem que o profissional de controladoria precisa ter uma formação direcionada com conhecimentos de áreas afins da Contabilidade como: Administração, Economia, Estatística e Informática, que servirão de base para o bom desempenho profissional, em virtude da competitividade do mercado em constante mudança.

E exatamente por isso, o presente estudo se torna relevante em fornecer subsídios sobre as novas competências que estão sendo demandadas pelas organizações para os profissionais da controladoria. Então, este estudo tem como objetivo identificar as principais competências exigidas aos Controllers para o exercício de suas atividades em empresas que estão instaladas em Pernambuco, Brasil. Seus achados poderão subsidiar novos estudos em realidades diversas, inclusive em relação à formação acadêmica desse profissional para atender essas demandas.

\section{Revisão da literatura}

\subsection{O profissional da Controladoria}

No Brasil, a Controladoria teve sua ascensão a partir da chegada das multinacionais no pais, na década de 60, e portanto, inicialmente os controllers eram principalmente estrangeiros, os quais foram responsáveis por treinar os funcionários brasileiros para o cargo, aprendendo principalmente a utilizar sistemas de informações gerenciais (Souza, 2015; Amorim \& Silva, 2017).

A Controladoria, como área de conhecimento, foi inicialmente vinculada especificamente à Contabilidade, contudo, vem se desenvolvendo com uma alternativa à contabilidade tradicional, pois busca prover os usuários internos das organizações com informações relevantes e temporais para a tomada decisão organizacional, segundo os estudos de Machado et al. (2010).

Oliveira, Perez Jr. e Silva (2011, p. 5) entendem a "Controladoria como o departamento responsável pelo projeto, elaboração, implementação e manutenção do sistema integrado de informações operacionais, financeiras e contábeis". Contudo, Beuren e Miller (2010) salientam que a controladoria pode ser implantada na estrutura organizacional de uma empresa como um órgão, setor ou departamento, mas também podem ser apenas implantadas suas atividades, como uma ampliação das atividades contábeis e gerenciais, que incluam uma maior preocupação com os controles internos e suprimento de informações para o processo decisório organizacional. 
Conforme apresentado, não há unanimidade quanto ao entendimento da controladoria nas organizações atuais. Na visão de Callado e Amorim (2017, p. 61) "é responsável pelo controle do processo de gestão, gerando e fornecendo informações diversas que podem ser de natureza operacional e estratégica, econômica, financeira e patrimonial, para a tomada de decisões". Este pensamento é semelhante ao de Oliveira et al. (2011).

Contudo, ainda não se tem um consenso sobre as funções e responsabilidades da Controladoria, uma vez que ela se altera significativamente dependendo da organização em que está inserida. Isto talvez ocorra devido sua origem ter sido da práxis empresarial, e que ainda está em consolidação no campo teórico (Lunkes et al. 2013; Vasconcelos \& Lima, 2017).

É possível perceber ao se analisar estudos nacionais e internacionais que o papel do controller vem se transformando com o passar do tempo, pois, nos estudos mais antigos, era identificado como um profissional que não estava muito envolvido no processo de gestão, sendo responsável por ações mais operacionais e de controle. Já em estudos mais recentes, foi identificado que grande parte está envolvida no apoio ao processo decisório organizacional (Borinelli, 2006; Zoni, \& Merchant, 2007; Vargas, \& Beuren, 2012; Lunkes et al. 2013; Schmidt, \& Santos, 2014). Este número crescente de pesquisas está ocorrendo talvez pela abrangência e amplitude das atividades desenvolvidas pela controladoria, e associado a isto, a necessidade de orientar o desenvolvimento dos controllers que nela atuam (Sousa \& Bassolli, 2013).

Portanto, o profissional da Controladoria ou controller precisa adaptar seu perfil profissional e de atuação à organização em que está inserido, pois dependendo da estrutura e cultura organizacional, serão exigidas competências diferenciadas (Schmidt \& Santos, 2014 e Oliveira, 2015). Schmidt e Santos (2006, p. 16) salientam que o controller "precisa conhecer e entender o funcionamento da cadeia de valores em que a organização está inserida, para que ele tenha capacidade de gerar informações para os gestores". Então, a função de controller exige, além de conhecimentos técnicos, determinado perfil profissional, pois sua credibilidade e comportamento ético influenciam nos resultados de seu trabalho e, consequente, credibilidade perante os gestores organizacionais (Leite, Zola, \& Silva, 2013).

Diante desse cenário, o controller é um profissional que deve possuir muitas competências não apenas técnicas, pois precisa ser apoio à gestão organizacional, respondendo rapidamente às demandas dos gestores em termos dos controles internos e externos. Precisa também conhecer bem a estrutura organizacional da empresa em que atua, para poder fornecer as informações coerentes à necessidade dos gestores.

Portanto, o profissional da Controladoria atua em várias funções, com destaque para: área contábil, gerencial, de custos, tributária, de controle interno, de risco e gestão de informações, na visão de Borinelli (2006). Em consonância, Ribeiro, Calijorne, Jurza, Ziviani e Neves (2017) afirmam que as organizações buscam profissionais com visão sistêmica e o controller está inserido neste novo perfil profissional, sendo elemento ativo na interação com as demais áreas, com acesso a múltiplas informações e se constitui em importante apoio para a tomada de decisão.

\subsection{Competências Profissionais}

O conceito de competência vem se construindo e se reconstruindo com o passar dos anos. Existem duas correntes dominantes: a americana, que a entende como CHA - conhecimentos, habilidades e atitudes, ou seja, do saber, saber fazer e saber agir responsável e reconhecido das atitudes, a qual pode ser mensurada, desenvolvida e aperfeiçoada, por meio de treinamentos e desenvolvimento, com defensores como: Parry (1996), Lawler III (1998), Perez (2005), 
Draganidis e Mentzas (2006), Le Deist e Winterton (2008) e Amorim, Veloso, Fischer e Dutra (2010) e seguidores. E a corrente francesa em que a competência é o eixo entre o relacionamento do indivíduo com os demais participantes da organização, contexto e período em que se efetiva, com autores e seguidores como: Zarifian (2001), Le Boterf (2003), Ruas (2005), Dutra (2010), Retour e Krohmer (2006), Zandonade e Bianco (2014), dentre outros.

Silva e Amorim (2012, p. 64), afirmam que "competência é mais do que um simples conjunto de atributos que definem a relação do colaborador com o trabalho". Pois ela se reinventa a cada decisão, ação e relação intra e inter organizacional, e segundo Ruas e Comini (2007) são resultado de trocas contínuas entre competências individuais, dos colegas e da organização como um todo. Porque "há uma interdependência entre funcionários e organização, em que a organização, ao progredir, desenvolve as pessoas e vice-versa" (Amorim, \& Silva, 2011, p. 109).

As competências ao serem classificadas, possuem diversas tipologias, mas podem ser divididas basicamente entre individuais e organizacionais (Campion et al., 2011). Fleury (2009) e Fleury e Fleury (2011) classificam as competências individuais em três categorias: Competências de Negócios (relacionadas à interação da empresa com as oportunidades e ameaças orientadas para as exigências do mercado, clientes e concorrentes); Competências Técnico-Profissionais (conhecimentos e experiência técnica do trabalhador, na área de atuação); e Competências Sociais (relações e interação das pessoas no trabalho em equipe, negociações, conflitos, etc.).

Reis, Sediyama, Moreira e Moreira (2015), salientam que o profissional da área contábil precisa desenvolver certas habilidades e competências pessoais, com ética e elevado comprometimento com sua própria profissão e organização em que está servindo, acrescido de sólidos conhecimentos teóricos sobre sua área e também áreas afins que se interligam e se influenciam mutuamente.

Beuren, Bogoni e Fernandes (2008) em seus estudos, realizaram uma pesquisa em cerca de 30 dissertações brasileiras sobre as funções da controladoria e identificaram que as principais funções são as seguintes: conhecimento contábil, gestão de informações, conhecimento de custos, controles internos e tributação, proteção e controle de ativos.

Em nosso levantamento bibliográfico para identificar as principais competências do controller, podem-se destacar: a elaboração de orçamentos; atividades de controle interno; elaboração de relatórios contábeis; auditoria interna; avaliação de desempenho econômico; sistemas de contabilidade; relatórios de governo e gestão fiscal (Horngren, Sundem, \& Stratton, 2004; Koliver, 2005; Zoni, \& Kenneth, 2007; Maas, 2007; Vargas, \& Beuren, 2012; Lunkes et al. 2013; Cavalcanti, Luca, Ponte, \& Gallon, 2012; Schmidt, \& Santos, 2014)

Dal Vasco, Daniel e Tarifa (2014, p. 10) defendem que cabe ao controller: "considerar os pontos financeiros fortes e fracos da empresa", como também identificar problemas atuais e futuros, apresentar alternativas de solução e monitorar os gestores no cumprimento do planejamento. "Precisam ser efetivos, motivar pessoas, saber resolver problemas financeiros" Dal Vasco et al. (2014, p. 13).

Portanto, o controller desenvolve as atividades de mediador entre as diversas áreas, departamentos e pessoas, nas organizações em que atua. Deve saber integrar ideias, criar um espírito de cooperação, ter flexibilidade e poder compreender, conversar e convencer. As habilidades sociais e de persuasão devem ser muito praticadas, bem como conhecer as áreas de atuação da organização, incluindo conhecimentos de contabilidade, finanças, produção, logística, vendas, marketing e gestão de pessoas, entre outras (Zoni, \& Kenneth, 2007; Cardoso, Riccio, Mendonça Neto, Oyadomari, 2010; Schmidt, \& Santos, 2014). 
Em relação às competências dos controllers, Callado e Amorim (2017), identificaram 61, em um vasto estudo bibliográfico em 30 publicações nacionais e internacionais, as quais foram distribuídas seguindo a classificação de competências de Fleury e Fleury (2009 e 2011). Salientando-se que Fleury e Fleury (2009 e 2011) estudaram como as competências individuais se classificam e não as competências dos controllers, especificamente.

Neste estudo, foram reescritas e aglutinadas/substituídas algumas competências ao rol dos autores Callado e Amorim (2017), a partir de novos estudos analisados citados anteriormente, perfazendo um total de 59 competências, sendo 20 competências técnicas, 21 competências sociais e 18 competências de negócios, listadas a seguir. Destaca-se que estas competências são utilizadas em intensidades diferentes dependendo da empresa em que o profissional está inserido. A Tabela 1 apresenta as competências técnicas, sociais e de negócios dos controllers.

\section{Tabela 1}

Competências Técnicas, Sociais e de Negócios dos Controllers.

\section{COMPETÊNCIAS}

\begin{tabular}{|c|c|c|c|}
\hline & $\begin{array}{l}\text { COMPETÊNCIAS } \\
\text { TÉCNICAS }\end{array}$ & COMPETÊNCIAS SOCIAIS & $\begin{array}{l}\text { COMPETÊNCIAS DE } \\
\text { NEGÓCIOS }\end{array}$ \\
\hline 1 & $\begin{array}{l}\text { Conhecimentos na área } \\
\text { financeira }\end{array}$ & Interage bem com as pessoas & Pensa e age estrategicamente \\
\hline 2 & $\begin{array}{l}\text { Conhecimentos na área } \\
\text { contábil }\end{array}$ & $\begin{array}{l}\text { Possui liderança e sabe gerir } \\
\text { pessoas }\end{array}$ & Orientação para Resultados \\
\hline 3 & $\begin{array}{l}\text { Conhecimentos na área } \\
\text { fiscal/tributária }\end{array}$ & $\begin{array}{l}\text { Flexibilidade nas relações } \\
\text { interpessoais }\end{array}$ & $\begin{array}{l}\text { Promove ações de interação da } \\
\text { empresa com seu ambiente }\end{array}$ \\
\hline 4 & $\begin{array}{l}\text { Conhecimentos na área de } \\
\text { tecnologia da informação }\end{array}$ & $\begin{array}{l}\text { Sabe formar equipes cooperativas } \\
\text { e comprometidas }\end{array}$ & $\begin{array}{l}\text { Sabe organizar o tempo para } \\
\text { realizar diversas atividades }\end{array}$ \\
\hline 5 & $\begin{array}{l}\text { Conhecimentos na área de } \\
\text { Recursos Humanos }\end{array}$ & $\begin{array}{l}\text { Estimula o desenvolvimento } \\
\text { profissional da equipe }\end{array}$ & $\begin{array}{l}\text { Foco na qualidade em todas as } \\
\text { decisões que toma }\end{array}$ \\
\hline 6 & $\begin{array}{l}\text { Conhecimentos na área } \\
\text { comercial/produção }\end{array}$ & $\begin{array}{l}\text { Comunica-se, oralmente com } \\
\text { clareza e objetividade }\end{array}$ & $\begin{array}{l}\text { Busca melhoria contínua dos } \\
\text { processos em que participa }\end{array}$ \\
\hline 7 & $\begin{array}{l}\text { Elabora diretrizes de controles } \\
\text { internos }\end{array}$ & $\begin{array}{l}\text { Capacidade de prever problemas } \\
\text { interpessoais }\end{array}$ & $\begin{array}{l}\text { Capacidade de tomar decisão } \\
\text { com imparcialidade }\end{array}$ \\
\hline 8 & Elabora o Orçamento Anual & Sabe negociar com pessoas & Realiza a gestão de contratos \\
\hline 9 & $\begin{array}{l}\text { Gerencia indicadores de } \\
\text { desempenho }\end{array}$ & Estimula o aprendizado da equipe & $\begin{array}{l}\text { Faz análise de risco } \\
\text { organizacional }\end{array}$ \\
\hline 10 & $\begin{array}{l}\text { Supervisiona as atividades nas } \\
\text { áreas de custos }\end{array}$ & $\begin{array}{l}\text { Capacidade de solucionar } \\
\text { problemas interpessoais }\end{array}$ & $\begin{array}{l}\text { Interage com os prestadores de } \\
\text { serviços/terceirizados }\end{array}$ \\
\hline 11 & $\begin{array}{l}\text { Fornece dados contábeis } \\
\text { oportunos e precisos }\end{array}$ & Tem integridade e confiança & $\begin{array}{l}\text { Relaciona-se com outras empresas } \\
\text { parceiras }\end{array}$ \\
\hline 12 & $\begin{array}{l}\text { Supervisiona o funcionamento } \\
\text { dos setores }\end{array}$ & $\begin{array}{l}\text { Escreve com clareza e } \\
\text { objetividade }\end{array}$ & $\begin{array}{l}\text { Realiza o acompanhamento } \\
\text { técnico dos projetos }\end{array}$ \\
\hline 13 & Supervisiona a contabilidade & $\begin{array}{l}\text { É persistente e não desiste frente } \\
\text { aos obstáculos }\end{array}$ & $\begin{array}{l}\text { Orientação para o } \\
\text { Cliente/Fornecedor }\end{array}$ \\
\hline 14 & $\begin{array}{l}\text { Fornece suporte informacional } \\
\text { à gestão }\end{array}$ & Postura proativa e realizadora & $\begin{array}{l}\text { Age com responsabilidade } \\
\text { socioambiental }\end{array}$ \\
\hline 15 & Elabora relatórios gerenciais & Busca o autodesenvolvimento & $\begin{array}{l}\text { Preocupação com segurança e } \\
\text { saúde na empresa }\end{array}$ \\
\hline 16 & $\begin{array}{l}\text { Assessora a cúpula } \\
\text { administrativa }\end{array}$ & Capacidade de autocrítica & $\begin{array}{l}\text { Busca inovação organizacional } \\
\text { (Pesquisa \& Desenvolvimento) }\end{array}$ \\
\hline 17 & Realiza análise de custos & $\begin{array}{l}\text { Gerencia conflitos no ambiente de } \\
\text { trabalho }\end{array}$ & $\begin{array}{l}\text { Promove ações de interação da } \\
\text { empresa com seu ambiente }\end{array}$ \\
\hline 18 & $\begin{array}{l}\text { Realiza análise de índices } \\
\text { contábeis }\end{array}$ & Tem controle emocional & $\begin{array}{l}\text { É criativo para solucionar } \\
\text { problemas empresariais }\end{array}$ \\
\hline
\end{tabular}


Tania Nobre Gonçalves Ferreira Amorim e Ladjane de Barros Silva

\begin{tabular}{lll}
19 & $\begin{array}{l}\text { Elabora o Planejamento } \\
\text { Financeiro Organizacional }\end{array}$ & $\begin{array}{l}\text { Adapta-se bem às mudanças e } \\
\text { novas situações }\end{array}$ \\
\hline 20 & Age como consultor interno & Sabe ouvir os outros \\
\hline 21 & & Sabe trabalhar em equipe \\
\hline
\end{tabular}

Fonte: Adaptado de Callado e Amorim (2017) e levantamento bibliográfico.

Em síntese, pode-se afirmar que não há consenso nos estudos nacionais sobre as competências dos controllers, uma vez que as organizações demandam diferentes atividades, em virtude da sua complexidade, cultura e momento, frente à acirrada concorrência e economia do país. Mas está se consolidando como lacuna teórica que, os controllers estão voltados não apenas a controles operacionais como outrora. Estão prestando apoio direto aos gestores, em suas demandas de gestão contábil, planejamento organizacional, avaliação de desempenho econômico, finanças, dentre outras atividades. Ou seja, concordando com Brewer (2008, p. 36) "em última instância, a responsabilidade dos controllers é gerar valor para os acionistas".

Assim, assume-se o pressuposto de que a formação do controller não pode ser baseada apenas em uma graduação, seja em Ciências Contábeis, Administração ou mesmo Economia, pois as competências que lhes estão sendo exigidas pelas empresas são abrangentes e interdisciplinares, relacionadas a essas diversas bases de conhecimentos das Ciências Sociais. Então, a pós-graduação específica em Controladoria pode ser uma alternativa que venha a se incorporar na formação do profissional que atua na controladoria no Brasil.

\section{Procedimentos metodológicos}

Com a finalidade de atingir o objetivo proposto para esta pesquisa, de identificar as principais competências exigidas aos Controllers para o exercício de suas atividades em empresas que estão instaladas em Pernambuco, Brasil, foi operacionalizada uma pesquisa descritiva e exploratória.

Foi utilizada uma amostra por conveniência, obtida a partir da rede de relacionamento de alunos de cursos de Pós-Graduação em Controladoria, em nível de especialização lato sensu e Mestrado em Controladoria stricto sensu, pertencentes a duas universidades federais em Pernambuco - Brasil. Foi solicitado aos alunos que buscassem pelo menos um profissional que estivesse ocupando a função de controller, contador gerencial ou controlador, em empresas, atuando em Pernambuco, para a aplicação de um questionário.

O questionário foi elaborado pela equipe de pesquisa, apresentando em um quadro síntese das principais competências do controller, baseadas em 30 estudos nacionais e internacionais de autores que estudam a temática há algum tempo e estão inseridos no levantamento bibliográfico, distribuindo essas competências segundo a classificação de Fleury (2009) e Fleury e Fleury (2011) em que as competências individuais são subdivididas em três categorias: Competências de Negócios, Competências Técnico-Profissionais e Competências Sociais.

Inicialmente foi realizado um pré-teste do instrumento. A amostra atingiu um total de 100 participantes, mas para as análises, dois questionários foram excluídos por estarem respondidos indevidamente. A primeira parte do questionário buscou traçar um perfil do respondente, a segunda da empresa e a terceira parte foi apresentada uma lista das principais competências atribuídas aos controllers, com uma escala Likert com as opções: não uso; uso pouco; geralmente uso e uso muito, para eles marcarem como as utilizam no seu dia a dia de trabalho.

A análise estatística dos dados considerou o Teste de Mann-Whitney U que é uma alternativa não paramétrica ao Teste T. Os cálculos e demais procedimentos estatísticos foram efetuados a partir do aplicativo computacional Statistica for windows.

Revista Ambiente Contábil - UFRN - Natal-RN. v. 11, n. 1, p. 220 - 236, Jan./Jun. 2019, ISSN 2176-9036. 


\section{Resultados e análise dos dados}

Em termos do quantitativo de funcionários e porte das empresas em que os controllers trabalham, a maioria era de pequeno e médio porte, com até 499 funcionários, mas 40,5\% eram de grande porte. Em relação ao ramo de atividade, a maioria trabalha em empresas prestadoras de serviço, seguida de indústrias e comércio. Em 51\% delas há um setor de controladoria estabelecido na estrutura organizacional. Este dado é interessante pois foi identificado que em torno de $17 \%$ das médias empresas possuem um setor de controladoria estruturado. Nas que não possuem uma unidade de Controladoria, há um profissional que realiza as atividades, investigando a ocorrência de desvios nos resultados e propondo medidas de controle como defendem Nascimento, Rosa, Santos e Tenório (2005), Giongo, Bianchi e Backer (2006), Nascimento e Reginato (2010) e Mosimann e Fisch (2009).

$\mathrm{O}$ perfil dos controllers identificado foi de maioria $(72,5 \%)$ do gênero masculino, confirmando estudos de Machado et al. (2010), Crispim et al., (2011) e Dal Vasco et al. (2014), e discordando do estudo de Araújo, Callado e Cavalcanti (2014) que identificou maioria feminina. São também em maioria jovens com menos de 40 anos, mas no outro extremo da faixa etária foi identificado $17,4 \%$ com mais de 50 anos.

A maioria dos controllers estudados tem até 10 anos de experiência na função e $93 \%$ têm formação superior, principalmente em Ciências Contábeis, com $70 \%$ deles pós-graduados, lato ou stricto sensu. Dados semelhantes são identificados em Vargas e Beuren (2012) e Araújo et al. (2014) em termos de formação e qualificação profissional. A grande maioria ocupa função gerencial $(85,7 \%)$ e assim, possui subordinados diretos, como também identificaram Floriani (2001) e Giongo et al. (2006).

Conforme explicitado anteriormente, a pesquisa buscou conhecer as competências individuais dos controllers e se tomou por base a classificação de competências individuais de Fleury (2009) e Fleury e Fleury (2011) em: competências de negócios, técnico-profissionais e sociais. O rol de competências dos controllers apresentado no quadro 1 e utilizado nesta pesquisa, foi construído a partir de Callado e Amorim (2017) e do levantamento bibliográfico realizado neste estudo.

As competências técnicas individuais que a maioria dos controllers afirmou "usar muito" foram seis, dentre as 20 listadas, apresentadas em ordem decrescente de uso: Assessora a cúpula administrativa, Conhecimentos na área contábil, Elabora relatórios gerenciais, Fornece suporte informacional à gestão empresarial, Realiza análise de custos e Conhecimentos na área financeira. Estas respostas confirmam estudos que identificam ênfase nas atividades relacionadas à contabilidade e apoio à gestão, realizadas pela controladoria, como Koliver (2005), Zoni e Kenneth (2007), Lunkes et al. (2013) e Vargas e Beuren (2012).

Schier (2010) e Lunkes et al. (2013) salientam que normalmente a função do controller é mais uma opção de atuação para os contadores, embora que também seja para profissionais da área de gestão, principalmente os que possuem formação em Administração, Economia, Estatística e Informática.

Pode-se destacar também a competência Conhecimentos na área de Recursos Humanos a qual foi citada pela maioria dos controllers como "geralmente usam". Já a competência Conhecimentos na área de Tecnologia da Informação (TI) grande parte afirmou "geralmente usa" $(47 \%)$ e a competência Supervisiona o funcionamento de todos os setores da empresa também $(42 \%)$. 
Já dentre as 18 competências de negócios apresentadas, a maioria respondeu "usar muito" quatro delas, apresentadas em ordem decrescente de uso: Pensa e age estrategicamente, Orientação para Resultados, Busca melhoria contínua dos processos em que participa, Foco na qualidade em todas as decisões que toma. Nota-se que estas competências estão relacionadas ao apoio estratégico dos controllers à cúpula organizacional. Autores como Lunkes et al. (2013) e Mosimann e Fisch (2009), dentre outros, destacam a importância dessas competências na atuação profissional dos controllers em seus estudos.

Quanto às 21 competências sociais listadas, a maioria dos controllers respondeu "usar muito", 14 delas, apresentadas em ordem decrescente de uso: Tem integridade e confiança, Busca o autodesenvolvimento, Postura proativa e realizadora, Sabe trabalhar em equipe, É persistente e não desiste frente aos obstáculos, Estimula o aprendizado da equipe, Estimula o desenvolvimento profissional da equipe, Interage bem com as pessoas, Possui liderança e sabe gerir pessoas, Comunica-se, oralmente com clareza e objetividade, Tem controle emocional, Adapta-se bem às mudanças e novas situações, Tem flexibilidade nas relações interpessoais e Sabe ouvir os outros.

Como pode ser visto, os participantes da pesquisa em maioria indicaram que as competências sociais são muito importantes para o papel de gestor que desempenham, o clima e ambiente social entre colegas, equipes, superiores e subordinados, bem como trabalho em equipe, flexibilidade e adaptabilidade ao novo, como também salientam Beuren et al. (2008), em seus estudos. Küpper (2005) defende que a capacidade de se impor do controller é dependente da capacidade de inspirar confiança na equipe e está relacionada ao nível de convencimento de seus argumentos para maior chance de êxito.

\subsection{Relações de significância entre as competências e o tamanho das empresas}

Foi realizada uma análise da significância estatística entre a intensidade de uso das competências individuais dos controllers e o tamanho das empresas em que trabalham. Entre as 20 competências técnicas listadas no questionário, apenas cinco apresentaram significância positiva em relação ao tamanho das empresas: Conhecimentos na área contábil, elabora o Orçamento Anual (Budget), Supervisiona a contabilidade, Gerencia indicadores de desempenho e Assessora a cúpula administrativa. Ou seja, apenas estas indicam que quanto maior a empresa, maior o seu uso.

Já em termos do uso das 21 Competências Sociais apresentadas e o tamanho das empresas pesquisadas, bem como em relação às 18 Competências de Negócios não foram identificadas nenhuma relação de significância entre a intensidade de uso e o tamanho das empresas. O que significa que são utilizadas em todas as empresas, independentemente de seu porte.

Essa constatação, apesar de surpreendente e inesperada, vem confirmar que as Competências Sociais e de Negócios apresentadas aos controllers participantes da pesquisa, baseadas no levantamento bibliográfico desenvolvido para a pesquisa, são efetivamente utilizadas, independente o porte das empresas em que atuam.

Teles, Lunkes, Nascimento, Schnorrenberger e Rosa (2012) afirmam que é no cenário atual que o controller tem assumido um papel proativo nas organizações, saindo de sua "zona de conforto" de atuar meramente nos controles financeiros e contábeis, para assumir maior responsabilidades como gerador de informações e apoio gerenciais, indicando e sugerindo novos caminhos a serem percorridos pela gestão organizacional. 


\section{Considerações finais}

O estudo apresentado teve como objetivo identificar as principais competências exigidas aos Controllers para o exercício de suas atividades em empresas que estão instaladas em Pernambuco, Brasil.

A controladoria vem intensificando sua presença institucional nas organizações contemporâneas, ampliando sua esfera de atuação, antes primordialmente em nível operacional e nas áreas financeira e contábil, para se consolidar como unidade de apoio à gestão organizacional nos diversos níveis decisórios, respondendo a problemas de natureza diversa e as mais variadas demandas dos gestores.

O profissional que atua na controladoria identificado no estudo, possui principalmente formação contábil, com responsabilidade sobre os controles internos e gerenciais das organizações, não mais exclusivamente em nível operacional, mas em nível gerencial e de apoio à cúpula administrativa. Possui grande experiência, formação em nível de pós-graduação e é principalmente do gênero masculino.

O controller estudado possui muitas competências individuais, tendo demonstrado que está efetivamente sendo apoio à gestão organizacional. Os pesquisados afirmaram utilizar muito, cerca de um terço das competências técnicas listadas, relacionadas à assessoria a cúpula administrativa, elaborando relatórios gerenciais e as demais relacionadas à área contábil e financeira, com também suporte informacional à gestão empresarial. Entre as competências de negócios apresentadas, a maioria respondeu "usar muito" apenas uma pequena parte, relacionadas a pensar e agir estrategicamente, orientação para resultados, melhoria contínua dos processos e foco na qualidade das decisões tomadas. E as competências sociais foram as que são mais utilizadas pelos controllers pesquisados, relacionadas a estimular e saber trabalhar em equipe, ter integridade, confiança, postura proativa e realizadora, buscar o autodesenvolvimento com persistência, possuir liderança e sabe gerir pessoas com flexibilidade, comunica-se com clareza e objetividade, tem controle emocional, adapta-se bem às mudanças e novas situações e sabe ouvir os outros.

Em termos da relação de significância das competências individuais dos contollers e o porte da empresa em que atuam, apenas um quarto das competências técnicas apresentaram correlação positiva em termos do porte da empresa, mas as competências sociais e de negócios não apresentaram qualquer correlação positiva com o porte da empresa em que o controller atua.

Apesar das limitações do estudo que foi realizado com uma amostra por conveniência com 100 profissionais que atuam como controllers, diversos achados confirmaram o que outros estudos nacionais e internacionais já apresentaram como competências do controller e novas informações foram apresentadas em termos de estudar as competências individuais dos controllers seguindo uma tipologia inovadora, em que as classifica como técnicas, de negócios e sociais, além de correlacioná-las ao porte da empresa em que atuam.

Sugere-se que estudos de natureza semelhante sejam desenvolvidos em outras realidades a fim de ampliar o entendimento sobre esse profissional que vem ganhando mais reconhecimento e importância na gestão organizacional atual. 


\section{Referências}

Amorim, T. N. G. F., \& Silva, L. de B. (2017). Profissionais da controladoria: competências e demandas organizacionais. Anais do XI Congreso Iberoamericano de Contabilidad de Gestión y el I Congreso Iberoamericano de Contabilidad y Finanzas, Lima, Peru, 1, p. 15-30.

Amorim, T. N. G. F. \& Silva, L. de B. (2011). Gestão por competências: Nuances e peculiaridades. Revista Reuna, 16(1), p. 103-119.

Amorim, T. N. G. F., Oliveira, A. R. L., Manzi, S. M. S., \& Cabral, M. F. (2017). Perfil e Competências do Controller em Empresas no Recife. Anais do Simpósio de Controladoria da UFRPE, Recife, PE, Brasil, 2.

Amorim, W. A. C., Veloso, E. F. R, Fischer, A. L., \& Dutra, J. S. (2010). Union Organizational Learning and Competency: A study about Brazilian and U.S. Organizations. Ide@as Concyteg, 4, p. 517-545.

Anthony, R. N., \& Govindarajan, V. (2004). Management Control Systems. Eleventh Edition, Irwin: Homewood.

Araújo, J. G. R., Callado, A. L. C., \& Cavalcanti, B. S. (2014). Habilidades e competências do controller: um estudo com alunos de cursos de pós-graduação em controladoria. Revista Catarinense da Ciência Contábil, 13(38), p. 52-64.

Barreto, M. da G. P. (2008). Controladoria na gestão: A relevância dos custos da qualidade. São Paulo: Saraiva.

Beuren, I. M., \& Almeida, D. M. (2012). Impactos da implantação das normas internacionais de contabilidade na controladoria: um estudo à luz da teoria da estruturação em uma empresa têxtil. Revista de Administração, 47(4), p. 653-670.

Beuren, I. M., \& Miiler, E. T. C. (2010). Evidências de institucionalização da controladoria em empresas familiares. Revista de Administração FACES, 9(2), p. 43-63.

Beuren, I. M., Bogoni, N. M., \& Fernandes, L. (2008). Análise da abordagem da controladoria em dissertações dos programas de pós-graduação em Ciências Contábeis. Revista Brasileira de Gestão de Negócios, 10(28), p. 249-263.

Borinelli, M. L. (2006). Estrutura conceitual básica de controladoria: sistematização à luz da teoria e da práxis. Tese de Doutorado em Ciências Contábeis, Universidade de São Paulo, São Paulo, SP, Brasil.

Brewer, P. C. (2008). Redefining management accounting. Strategic Finance, Montvale, 89(9), p. 35-43.

Broadbent, J., \& Laughlin, R. (2005). Organizational and accounting change: Theoretical and empirical reflections and thoughts on a future research agenda. Journal of Accounting \& Organizational Change, 1(1), p. 7-25.

Buscoa, C., Quattroneb, P., \& Riccabonia, A. (2007). Management Accounting: Issues in interpreting its nature and change. Management Accounting Research, 18(2), p. 125-149.

Callado, A. A. C., \& Amorim, T. N. G. F. (2017). Competências da Função de Controller em Hotéis de Grande Porte da Região Metropolitana do Recife. Revista Evidenciação Contábil \& Finanças, 5(2), p. 57-73. 
Campion, M. A., Fink, A. A., Ruggeberg, B. J., Carr, L., Philips, G. M., \& Odman, R. B. (2011). Doing competencies well: best practices in competency modeling. Personnel Psychology, 64(1), p. 225-262.

Cardoso, R. L., Riccio, E. L., Mendonça Neto, O. R., \& Oyadomari, J. C. (2010). Entendendo e explorando as competências do contador gerencial: uma análise feita pelos profissionais. Advances in Scientific and Applied Accounting, 3(3), p. 353-371.

Cavalcante, D. S., Luca, M. M. M. de, Ponte, V. M. R., \& Gallon, A. V. (2012).

Características da controladoria nas maiores companhias listadas na BM\&F Bovespa. Revista Universo Contábil, 3(8), p. 113-134.

Crispim, G., Cabral, L. M. M. do A. C., \& Libonati, J. J. (2011). Aspectos comportamentais: A controladoria como fator de influência no comportamento humano. Advances in Scientific and Applied Accounting, 4(3), p. 379-405.

Dal Vasco, D., Daniel, M. M., \& Tarifa, M. R. (2014). Estudo do Perfil, Conhecimento, Papel e Atuação do Controller em Cooperativas. Revista de Finanças Aplicadas, 2, p. 1-31.

Draganidis, F., \& Mentzas, G. (2006). Competency based management: a review of systems and approaches. Information Management \& Computer Security, 14(1), p. 51-65.

Dutra, J. S. (2010). Competências: conceitos e instrumentos para gestão de pessoas na empresa moderna. São Paulo: Atlas.

Fleury, M. T. L. (2009). Organizational Culture and the Renewal of Competences. Brazilian Administration Review, 6, p. 1-14.

Fleury, A. C. C., \& Fleury, M. T. L. (2009). Understanding the Strategies of Late Movers in International Manufacturing. International Journal of Production Economics, 122, p. 340-350.

Fleury, A. C. C., \& Fleury, M. T. L. (2011). Estratégias empresariais e formação de competências: um quebra cabeça caleidoscópico da indústria brasileira. $3^{\mathrm{a}}$ ed. $6^{\mathrm{o}}$ reipr. São Paulo: Atlas.

Floriani, A. R. (2001). Controladoria como geradora de informações para subsidiar decisões administrativas. Revista de Negócios, 6(3), p. 29-38.

Giongo, J., Bianchi, M. \& Backer, R. G. (2006). A participação da controladoria no processo de gestão organizacional. Revista Contexto, 6, p. 69-91.

Gomes, C. V., Souza, P. de, \& Lunkes, R. J. (2014). O perfil do profissional da controladoria solicitado por empresas brasileiras. Revista de Globalização, Competitividade e Governabilidade, Madrid, 8(1), p. 34-50.

Horngren, C. T., Sundem, G. L., \& Stratton, W. O. (2004) Contabilidade gerencial. São Paulo: Prentice-Hall.

Koliver, O. (2005). A contabilidade e a controladoria: Tema atual e de alta relevância para a profissão contábil. Porto Alegre: Conselho Regional de Contabilidade do Rio Grande do Sul.

Küpper, P. (2005). Controlling: Konzeption, Aufgaben und Instrumente. Berlin: MSG. Lawler III, E. E. (1998). From job-based to competency-based organizations. Journal of Organizational Behavior, 15(1), p. 03-15.

Le Boterf, G. (2003). Desenvolvendo a competência dos profissionais. Porto Alegre: Artmed. 
Le Deist, F. D., \& Winterton, J. (2008). What Is Competence? Human Resource Development International, 8(1), p. 27-46.

Leite, G., Zola, P., \& Silva, E. (2013). Um estudo sobre o perfil do profissional de controladoria. Anais do Congresso de Gestão Estratégica: Criatividade e Interatividade, Ponta Grossa, PR, Brasil, 10.

Lunkes, R. J., Schnorrenberger, D., \& Rosa, F. S. (2013). Funções da Controladoria: Uma análise no cenário brasileiro. Revista Brasileira de Gestão de Negócios, 15(47), p. 283-299.

Machado, A. O., Lunkes, R. J., Petri, S. M., \& Rosa, F. S. (2010). Competências do Controller: um estudo nas 100 maiores empresas de Santa Catarina. Revista Pensar Contábil, 12(47), p. 26-34.

Mass, V. S. (2007). The effect of controller involvement in management on performance measurement system gaming. Dissertation Management, Faculty of Economics and Business. Amsterdam.

Monteiro, J. M., \& Barbosa, J. D. (2011). Controladoria empresarial: gestão econômica para as micro e pequenas empresas. Revista da Micro e Pequena Empresa, 2(5), p. 38-59.

Morante, A. S., \& Jorge, F. T. (2008). Controladoria: Análise financeira, planejamento e controle orçamentário. São Paulo: Atlas.

Mosimann, C. P., \& Fisch, S. (2009). Controladoria: Seu papel na administração de empresas. São Paulo: Atlas S.A.

Nascimento, A. M., \& Reginato, L. (2010). Controladoria: Instrumento de apoio ao processo decisório. São Paulo: Atlas.

Nascimento, F. R. V. do, Rosa, A. L. T., Santos, S. M. dos, \& Tenório, J. N. B. (2005). A controladoria como suporte ao processo de gestão numa empresa do comércio varejista. Revista de Contabilidade do Mestrado de Ciências Contábeis da UERJ, 10(2), p. 11-26.

Oliveira, C. R. (2015). A Importância da Controladoria e do Planejamento para Pequenas e Médias Empresas. Monografia de Especialização, Universidade Federal do Paraná, Curitiba, PR, Brasil.

Oliveira, L. M., Perez Jr, J. H., \& Silva, C. A. S. (2011). Controladoria Estratégica: textos e casos práticos com solução (8a ed.). São Paulo: Atlas.

Oro, I. M., Beuren, I. M., \& Carpes, A. M. S. (2013). Competências e habilidades exigidas do controller e a proposição para sua formação acadêmica. Revista Contabilidade Vista \& Revista, 24(1), p. 15-36.

Parry, S. B. (1996). The quest for competencies. Training Magazine, 33(7), p. 48-54.

Perez, M. I. L. (2005). Competência: uma noção plástica, polissêmica e polimorfa. Práxis Educacional, 1(1), p. 57-65.

Reis, A. de O., Sediyama, G. A. S., Moreira, V. de S., \& Moreira, C. C. (2015). Perfil do Profissional Contábil: habilidades, competências e imagem simbólica. Revista Contemporânea de Contabilidade, 12(25), p. 95-116.

Retour, D., \& Krohmer, C. (2006). La compétence collective comme maillon clé de la gestion des competences. In: C. Defelix, A. Klasferd, \& E. Oiry. Nouveaux regards sur la gestion des compétences. Paris: Vuibert. 
Ribeiro, J. S. de A. N., Calijorne, M. A., Jurza, P. H., Ziviani, F., \& Neves, J. T. de R. (2017). Gestão do conhecimento e desempenho organizacional: integração dinâmica entre competências e recursos. Perspectivas em Gestão \& Conhecimento, 7, p. 4-17.

Ruas, R. (2005). Gestão por Competências: uma contribuição à estratégia das organizações. In: R. Ruas, C. S. Antonello, \& L. H. Boff (Org.). Os Novos Horizontes da GestãoAprendizagem Organizacional e Competências (15 a ed.). São Paulo: Bookman.

Ruas, R., \& Comini, G. M. (2007). Aprendizagem e Desenvolvimento de Competências: Articulando teoria e prática em programas de pós-graduação em formação gerencial. Cadernos EBAPE.BR - FGV. Online, p. 36-49.

Schier, C. U. C. (2010). Controladoria como instrumento de gestão (2 a ed.). Curitiba: Juruá.

Schmidt, P., \& Santos, J. L. (2006). Fundamentos de controladoria. São Paulo: Atlas.

Schmidt, P., \& Santos, J. L. dos. (2014). A Controladoria e a análise discriminante do consumidor do e-commerce. Revista Internacional de Economia y Gestion de las Organizaciones, 3, p. 1-15.

Silva, L. B., \& Amorim, T. N. G. F. (2012). Estudos sobre competências: uma análise dos artigos publicados nos ENANPADs. Revista Reuna, 17(1), p. 61-76.

Souza, C. T. D. (2015). A evolução da Controladoria: Um estudo no Brasil. Dissertação de mestrado, Faculdade de Ciências Econômicas da Universidade Federal do Rio Grande do Sul, Porto Alegre, RS, Brasil.

Sousa, K. A., \& Bassolli, R. (2013). Contabilidade gerencial um instrumento de apoio a gestão para a tomada de decisão.Instituto cuiabano de educação. Recuperado a partir de http://www.ice.edu.br/TNX/storage/webdisco/2013/12/13/outros/555a4ca9721653f157cd8 7c71daed621.pdf.

Souza, F. J. V., Barros, C. C., Araujo, O. A., \& Silva, M. C. (2013). Perfil dos Artigos Sobre Controladoria Publicados em Periódicos Nacionais de Contabilidade. Revista Catarinenseda Ciência Contábil, 12(37), p.35-50.

Teles, J., Lunkes, R. J., Nascimento, C., Schnorrenberger, D., \& Rosa, F. S. (2012). Perfil do controller no setor hoteleiro: comparativo entre pesquisas no Brasil, China, Estados Unidos e Reino Unido. Turismo: Visão e Ação, 14(3), p. 386-400.

Vargas, J. A., \& Beuren, I. M. (2012). O envolvimento do controller no processo de gestão: um estudo em empresas brasileiras. Advances in Scientific and Applied Accounting, 5(3), p. 405-426.

Vasco, D. D., Daniel, M. M., \& Tarifa, M. R. (2014). Estudo do perfil, conhecimento, papel e atuação do controller em cooperativas. Revista de Finanças Aplicadas, 2(1), 1-31.)

Vasconcelos, G., \& Lima, A. C. (2017). Análise Bibliométrica da Produção Científica acerca da Controladoria. Management Control Review, 2(1), p. 31-49.

Vogt, M., Degenhart, L., \& Lavarda, C. E. F. (2017). Motivações, Habilidades e Competências do Controller na Percepção de Alunos que Cursam Pós-Graduação em Controladoria. Revista Catarinense da Ciência Contábil, 16(48), 105-123. 
Zandonade, V., \& Bianco, M. de F. (2014). O trabalho abstrato e a noção de competências: discutindo essa inter-relação no contexto do trabalho industrial. Revista $O \& S, 21(70)$, p. 443 466.

Zarifian, P. (2001). Objetivo competência: por uma nova lógica. São Paulo: Atlas.

Zoni, L., \& Kenneth, M. (2007). Controller involvement in management: an empirical study in large Italian corporations. Journal of Accounting \& Organizational Change, 3(1), p. 29-43. 